\title{
The M3A multi-sensor buoy network of the Mediterranean Sea
}

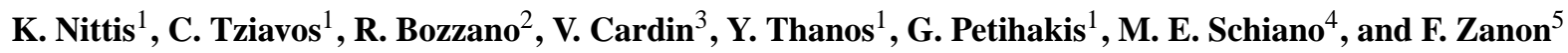 \\ ${ }^{1}$ Hellenic Centre for Marine Research, Institute of Oceanography, Athens, Greece \\ ${ }^{2}$ Consiglio Nazionale delle Ricerche, Istituto di Studi sui Sistemi Intelligenti per l'Automazione, Genova, Italy \\ ${ }^{3}$ Istituto Nazionale di Oceanografia e di Geofisica Sperimentale, Department of Oceanography, Trieste, Italy \\ ${ }^{4}$ Consiglio Nazionale delle Ricerche, Istituto di Scienze Marine, Genova, Italy \\ ${ }^{5}$ Tecnomare SpA, Venezia, Italy
}

Received: 18 April 2006 - Published in Ocean Sci. Discuss.: 31 August 2006

Revised: 16 January 2007 - Accepted: 9 May 2007 - Published: 21 May 2007

\begin{abstract}
A network of three multi-sensor timeseries stations able to deliver real time physical and biochemical observations of the upper thermocline has been developed for the needs of the Mediterranean Forecasting System during the MFSTEP project. They follow the experience of the prototype M3A system that was developed during the MFSPP project and has been tested during a pilot pre-operational period of 22 months (2000-2001). The systems integrate sensors for physical (temperature, salinity, turbidity, current speed and direction) as well as optical and chemical observations (dissolved oxygen, chlorophyll-a, PAR, nitrate). The south Aegean system (E1-M3A) follows a modular design using independent mooring lines and collects biochemical data in the upper $100 \mathrm{~m}$ and physical data in the upper $500 \mathrm{~m}$ of the water column. The south Adriatic buoy system (E2M3A) uses similar instrumentation but on a single mooring line and also tests a new method of pumping water samples from relatively deep layers, performing analysis in the protected "dry" environment of the buoy interior. The Ligurian Sea system (W1-M3A) is an ideal platform for air-sea interaction processes since it hosts a large number of meteorological sensors while its ocean instrumentation, with real time transmission capabilities, is confined in the upper $50 \mathrm{~m}$ layer. Despite their different architecture, the three systems have common sampling strategy, quality control and data management procedures. The network operates in the Mediterranean Sea since autumn 2004 collecting timeseries data for calibration and validation of the forecasting system as well for process studies of regional dynamics.
\end{abstract}

Correspondence to: $\mathrm{K}$. Nittis

(knittis@ath.hcmr.gr)

\section{Introduction}

Operational monitoring and forecasting of marine environmental conditions is a necessary tool for the effective management and protection of the marine ecosystem. It requires the use of multi-variable real-time measurements combined with advanced physical and ecological numerical models. Fixed oceanographic buoys contribute significantly to operational monitoring especially when high frequency and multiple parameters are among the requirements (Glenn et al., 2000).

Such a multi-sensor buoy system was developed for the needs of the Mediterranean Forecasting System (MFS) during the EU funded MFSPP project (1998-2001). The overall aim of MFS, according to its science plan, is the prediction of coastal primary producers' variability from the time scales of days to months (Pinardi and Flemming, 1998). Among the main goals of its pilot phase (MFSPP) was to demonstrate that multi-parametric operational monitoring and near real time (NRT) forecasts of the large-scale basin currents are feasible (Pinardi et al., 2003). The Mediterranean Moored Multi-sensor Array (M3A) is one of the observing components of MFS and was designed to provide real time biochemical data of the euphotic zone $(0-100 \mathrm{~m})$ and physical parameters of the upper thermocline $(0-500 \mathrm{~m}$, Nittis et al., 2003). The MFS observing system also includes a) the VOS system for collection of XBT profiles along selected transects, b) the ARGO floats for temperature/salinity profiles and estimates of the deep circulation characteristics, c) satellite remote sensing for SST, SLA and Ocean Colour and d) an experimental Glider for temperature and salinity profiles along a single transect. The M3A data would be used for calibration and validation of the hydrodynamic and ecosystem models, for interpretation/calibration of satellite ocean colour data and for future assimilation into regional ecosystem models.

Published by Copernicus GmbH on behalf of the European Geosciences Union. 


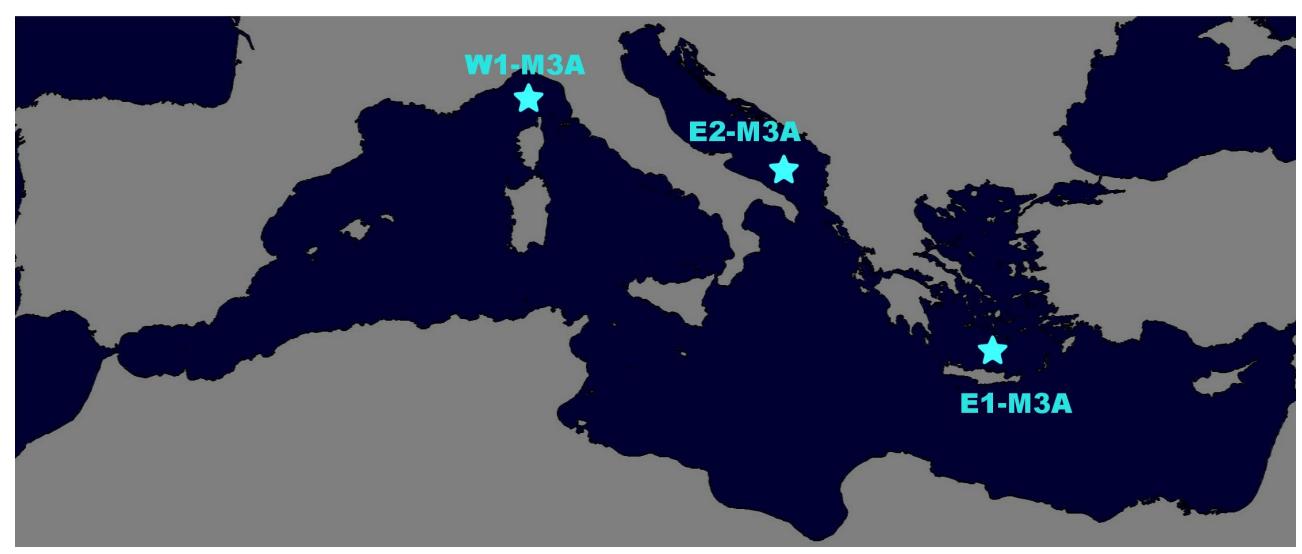

Fig. 1. Location of the M3A moorings in the Mediterranean Sea.

The development of the prototype M3A system was based on the experience of the Tropical Atmosphere-Ocean (TAO) array of the Equatorial Pacific (McPhaden et al., 1998) and similar developments on multi-parametric measurements at the Bermuda Test-Bed Mooring (Dickey et al., 1998) and the HALO/ALOHA station of the HOT program (Chiswell and Lucas, 1990). The goal was to combine the operational capabilities of the Atlas moorings with the multiparametric configurations of the BTM \& HALO systems. Furthermore, its design took into account the requirements of the MFS Science Plan (open sea system, multi-parametric observation, real-time transmission) and the need for easy and costeffective maintenance. Its pilot operation during 2000-2001 provided valuable time series for studies of ocean dynamics in the Cretan Sea (Cardin et al., 2003) and calibrationvalidation of regional ecosystem models (Triantafyllou et al., 2003).

During the MFSTEP project (Pinardi et al., 2005), the prototype M3A system has been upgraded, using the experience of its pilot operation, and was re-deployed in the south Aegean Sea (E1-M3A) while two more similar systems have been developed: the first one in the southern Adriatic Sea (E2-M3A) and the second in the Ligurian Sea (W1-M3A). In this way, the basis of a coordinated, multiparametric, opensea, buoy network for the Mediterranean basin has been established (Fig. 1). The development of the two new systems was based on upgrade of existing buoys that already had a long record of operation, and/or commitments for operation through national initiatives. The E2-M3A system is an upgrade of the BOMA buoy that has been developed through a project funded by the Italian Ministry of University, Scientific and Technological Research. Partnership included ENEA, TECNOMARE, OGS, IDROMAR, CNR-IOF (Tenomare, 2004). The W1-M3A system is an upgrade of the ODAS Italia-1 buoy that operates in the Ligurian Sea since the begin of the 1970s (Cavaleri, 1984).

The areas where the three stations operate represent different hydrodynamic and ecosystem regimes of the Mediter- ranean Sea. The prototype M3A (E1-M3A) continues its operation in the Cretan Sea (south Aegean Sea, $35^{\circ} 39^{\prime} \mathrm{N}$, $24^{\circ} 58^{\prime} \mathrm{E}$ ), an extremely oligotrophic area where dense waters with intermediate and deep characteristics are formed during wintertime convection (Theocharis et al., 1999). The 2nd system (E2-M3A) is deployed in the southern Adriatic Sea $\left(41^{\circ} 18^{\prime} \mathrm{N}, 17^{\circ} 48^{\prime} \mathrm{E}\right)$, at about $1200 \mathrm{~m}$ depth, another well-known area of dense water formation through open-sea convection. The center of the Southern Adriatic is an area where vertical mass transfer (upwelling, wintertime convection) has a rather prominent role in distributing physical and chemical water properties and controlling the primary production (transfer of nutrients in the euphotic zone). Upwelling is determined by the intensity of the cyclonic circulation that in turn depends on the climatic conditions over the area (Gačić et al., 2002). The site is therefore appropriate for moored measurements since it is possible, under certain circumstances, to neglect contributions of lateral advection processes. The 3rd system (W1-M3A) is deployed in the Ligurian Sea of the Western basin, one of the most dynamically active and productive areas within the whole Mediterranean $\left(43^{\circ} 49^{\prime} \mathrm{N}, 9^{\circ} 07^{\prime} \mathrm{E}\right)$. A permanent cyclonic circulation with seasonal and interannual variability triggered by the Tyrrhenian current dominates the area. During the winter, processes of dense water formation often occur (Astraldi, 1990, 1992). Furthermore, this is an area that has been intensively monitored for several years in terms of surface atmospheric parameters (Sparnocchia et al., 2006) and water circulation.

The architecture of the three M3A systems and the results of their operation during 2004-2006 are presented in this paper. Section 2 provides technical details on the design and instrumentation of the three systems. Quality control and data management issues are discussed in Sect. 3. The operation of the network during the MFSTEP project is described in Sect. 4 and sample timeseries are presented. The conclusions and future plans are summarized in Sect. 5. 


\section{M3A systems' design}

The development of the M3A network was based, in large, on upgrades of existing buoys and, thus, common architecture could not be used for the three systems. However, efforts have been made to maintain common components such as: sampling strategy, quality controls/checks, data management procedures, signaling devices as required by the international regulations, as well as common instrumentation when new investments could be made. The design and technical characteristics of the three systems are presented in the following paragraphs.

\subsection{The E1-M3A system}

\subsubsection{Overall design and surface buoy}

E1-M3A is an evolution of the prototype M3A system (Nittis et al., 2003) with the following upgrades: a) a new telemetry system based on Iridium satellite is used b) a new pair of underwater acoustic modems have been installed and c) antifouling methods have been tested and used for the optical sensors. The above upgrades were necessary to overcome the problems detected during the pilot operation of the system: the real time delivery of data and the quality of biochemical observations due to fouling. The system is composed by three independent mooring lines (Fig. 2). The central one (line 1) hosts the surface buoy and the sensors for physical parameters at deep layers $(100-500 \mathrm{~m})$. The two peripheral moorings host the sensors for physical and biochemical parameters in the upper layer (line 2) as well as the $0-500 \mathrm{~m}$ current profiler (line 3).

This modular configuration of E1-M3A allows separate, and thus easier, maintenance of lines 2 and 3 that need more frequent maintenance (every 3-4 months) and can be handled by a medium size vessel. The central mooring line has a lower maintenance frequency (1-2 years) but, due to the size of the surface buoy, it requires the presence of a larger research vessel. All mooring lines are equipped with acoustic releasers that allow easy recovery and re-deployment of the system.

The surface buoy (wave rider "Medusa") has a diameter of $3.60 \mathrm{~m}$ and a total weight of $1150 \mathrm{~kg}$. Its discus-shaped floating body is constructed from fibre-reinforced plastic (FRP), while the core is filled with light, high quality polyurethane material (divinycell). The power supply system consists of four rechargeable batteries of $220 \mathrm{Ah}$ capacity, which in practice can provide 14 days of independent operation without recharging. The batteries are of lead-acid type and can be recharged both through solar panels (180 Watt nominal power) and/or through wind generator.

\subsubsection{Instruments and sensors}

The surface buoy is equipped with sub-surface (1.5 m depth) sensors for temperature and conductivity (Aanderaa 3211) as

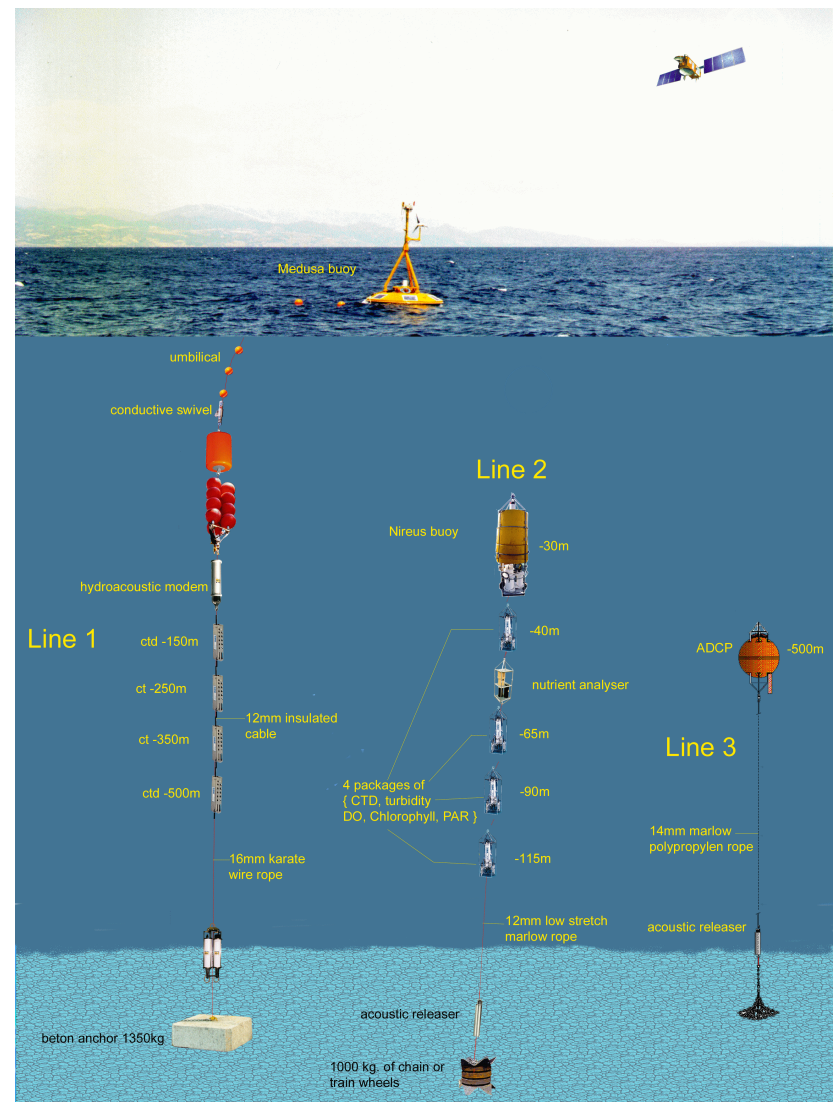

Fig. 2. Outline of the E1-M3A system.

well as wave and meteorological sensors (wind speed and direction, air temperature, atmospheric pressure, humidity, wave height and direction). For the measurement of conductivity and temperature at deep layers two CT (250 and $350 \mathrm{~m})$ and two CTD (250 and $350 \mathrm{~m}$ ) instruments (SBE-37 IM) are attached on the central mooring line.

Mooring line 2 is hosting four CTD probes (SBE-16) at 40, 65, 90 and $115 \mathrm{~m}$. Apart of temperature, conductivity and pressure sensors, each probe is equipped with a transmissometer (Wetlabs C-Star), a chlorophyll fluorometer (Wetlabs WETStar), a PAR (Photosynthetically Active Radiation) sensor (Li-Cor LI-193-SA) and a dissolved oxygen sensor (SBE-23B). A NAS2 nutrient (nitrate) analyzer of WSOCEAN at $45 \mathrm{~m}$ depth has been used in the previous deployments but has been removed in 2004 due to malfunction. The third mooring line (3) hosts the RDI $75 \mathrm{kHz}$ Long Ranger ADCP. This device is at $500 \mathrm{~m}$ depth, measuring the current profile from that depth up to surface.

In order to reduce biofouling effects on the optical sensors, all the line 2 probes are equipped with canisters of bromide tablets while all plastic tubes have been replaced by copper. The bromine canister is attached to the SBE-16 flushing circuit between the fluorometer and the transmissometer. It maintains brominated water that prevents the growth of 


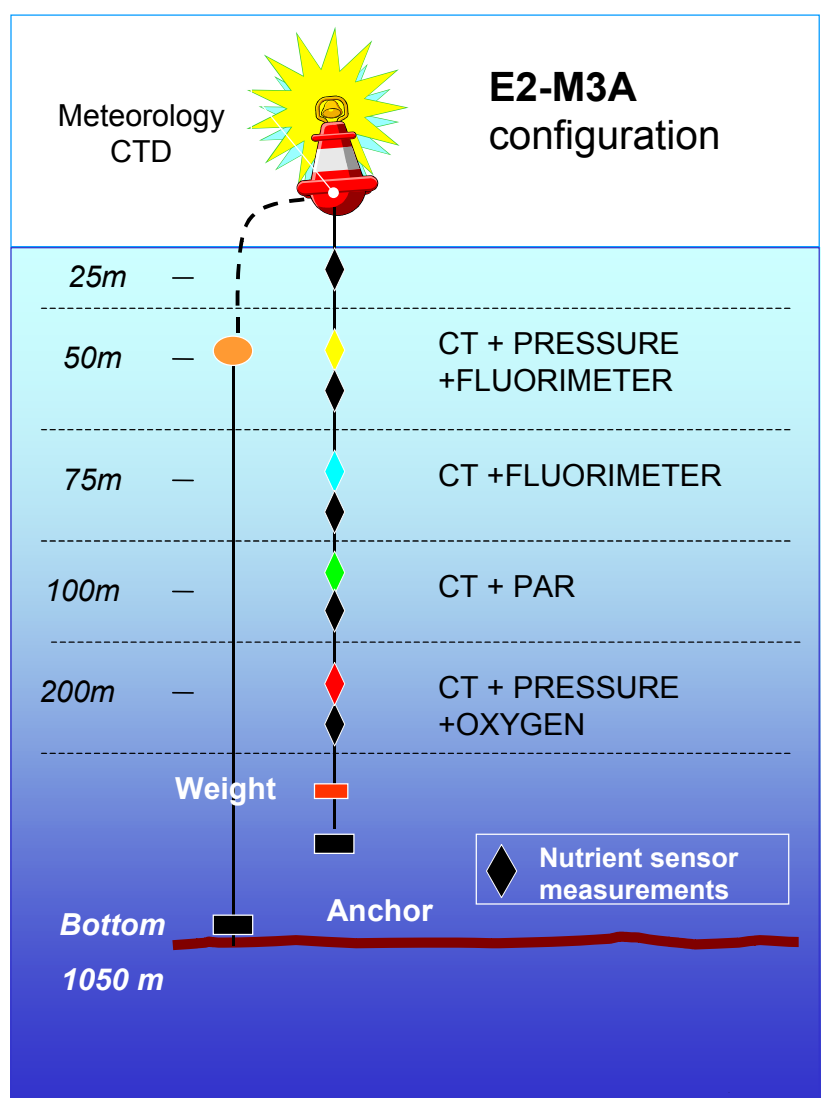

Fig. 3. Outline of the E2-M3A system.

phytoplankton inside the circuit and the sensors, in-between measurements. The two methods have been tested during a dedicated experiment in the Aegean Sea and have proved to offer an efficient anti-fouling protection for at least three months (Petihakis et al., 2007).

\subsubsection{Control systems and data telemetry}

The system control and data acquisition unit of E1-M3A is based on an embedded 80486 PC. It includes analogue to digital conversion cards with 16 differential inputs, hard disk of $255 \mathrm{MB}, 1$ parallel and 6 serial ports, a programmable timer and voltage regulators. For data telemetry and remote control of the system an Iridium modem (A3ALA-I form NAL Res. Corp.) is used. A secondary, but more frequently used due to lower cost, communication method is through the GSM network that has an increasing coverage in the Aegean Sea. Both systems allow two-way communication between the operational centre and E1-M3A. The position of the central line is controlled through the GPS of the surface buoy while lines 2 and 3 are equipped with Argos beacons (OrcaBASM500) that transmit the position if the mooring line is cut and the flotation device comes to surface.

Data are transferred from the CTD instruments of line 1 to the surface buoy by a $600 \mathrm{~m}$ inductive-modem cable. This cable is connected to the subsurface umbilical by a conductive swivel at $30 \mathrm{~m}$ that allows the free rotation of the surface buoy, but in the same time it conducts the signal of the deep sensors. At $30 \mathrm{~m}$ depth, a hydroacoustic modem (Linkquest UWM300) receives the data from mooring line 2 and transfers them to the surface buoy through the umbilical.

The four probes of line 2 are networked via an RS-485 interface. A pressure container at $35 \mathrm{~m}$ depth is hosting the computer that controls line 2 , stores the data and transmits them to mooring line 1 through the hydro-acoustic modem that is attached on the flotation device above the pressure container.

The ADCP system of line 3 does not include telemetry through the surface buoy since the large volume of data does not allow real time transmission. With a sampling interval of $30 \mathrm{~min}$ the autonomy of the ADCP is approximately 6 months, which is the maintenance interval for mooring line 3.

Additional technical information for the E1-M3A system including sensors characteristics (models, accuracy etc.) are provided by Nittis et al. (2003).

\subsection{The E2-M3A system}

\subsubsection{Overall design and surface buoy}

The configuration of the E2-M3A system follows the same principles applied as the M3A buoy in the Cretan Sea. However, choice of instruments, measurement depths and parameters to be monitored, are adapted to specific oceanographic and bio-geo-chemical properties of the Adriatic Sea. The E2M3A system is characterized by a surface buoy and a single mooring line (Fig. 3). The buoy hull of welded steel construction has a discus shape ( $6 \mathrm{~m}$ diameter, $1.4 \mathrm{~m}$ height), which provides three main compartments, provision for installation of sensors, ballast compartments and provision for the attachment of the superstructure.

The buoy configuration includes data acquisition and control electronics, power management systems, battery packs, photovoltaic panels, status monitoring sensors (such as GPS, battery voltage and current, panels current, internal temperatures, tilt, heading, acceleration, water detectors etc.).

The ballast compartments have the capacity for $1135 \mathrm{~kg}$ (total) of water, which may be used to trim and/or ballast the buoy to the desired displacement as defined by the following information:

- Displacement $13600 \mathrm{~kg}$

- Hull weight $9080 \mathrm{~kg}$

- Mast weight $320 \mathrm{~kg}$

- Payload 2700 kg max

- Reserve (trim, ballast, payload) $1500 \mathrm{~kg}$ 


\subsubsection{Instruments and sensors}

The scientific payload of the E2-M3A system can be grouped into 3 main classes based on the type of measurement produced and/or on their position along the buoy's body. The first group is dedicated to air-sea interface measurements and includes a meteorological station (RM Young) and a hull mounted C/T sensor (SeaBird SBE-37SI). The second group includes the four probes (SBE-16) attached on a $200 \mathrm{~m}$ inductive cable and performing measurements of: CTD at 50, 75, 100 and $200 \mathrm{~m}$; fluorescence at $50 \mathrm{~m}$ and $75 \mathrm{~m}$; dissolved oxygen at $200 \mathrm{~m}$; PAR measurements at $100 \mathrm{~m}$. The third group consists of an automatic water sampling system that makes available onboard the buoy seawater pumped from up to 5 different depths. This makes possible to carry out, using a single nutrient analyser (WS EnviroTech NAS-2E) and multiparametric probe (Idromar IM-51), measurements of nitrate, fluorescence and turbidity parameters at depths of 25 , $50,75,100$ and $200 \mathrm{~m}$. Maintenance of the nutrient analyser, e.g. for reagent replacement, is also greatly simplified (no underwater operation necessary).

\subsubsection{Control systems and data telemetry}

Other type of measurements aiming to control the correct functioning of the system are also carried out by E2-M3A. The GPS receiver is necessary to keep the clock of the data acquisition and control electronics correctly synchronized with the Greenwich Meridian Time and to get the correct position of the buoy: detection of a position out of a pre-defined "Watch Circle" will generate an alarm condition. The water detectors (one for each buoy compartment) will generate an alarm condition in case of detection of water at a certain level above the buoy floor. Finally, a Power System Monitoring Unit is used to detect failures of power.

Regarding the operational mode of the buoy, there are two different states: IDLE and MISSION mode. In the IDLE mode only GPS and Water Detectors operate and in case of an alarm condition (buoy out of the watch circle or water detected in a compartment) a message is sent through the telemetry system and the reception/execution of commands/data requests is possible via the communication system. In the MISSION mode the buoy automatically manages the acquisition of scientific data according to the programmed configuration, the organization of collected data into files, the calculation of hourly reduced data, their daily transmission to the land station and back-up storage in internal mass memory.

Data transmission is carried out via cellular modem. In particular, every day the buoy produces a file named *.SUM containing the reduced hourly data relevant to all scientific payload and status parameters. Two other files are produced, to enable further in-house processing on a significant subset of the original (raw) data acquired:
- file *.MET (produced hourly) containing 20' of meteorological data acquired at $2 \mathrm{~Hz}$;

- file *.SEA (produced every $3 \mathrm{~h}$ ) containing 20' of buoy motion data (pitch, roll, heading) acquired at $2 \mathrm{~Hz}$.

To manage these data and convert them in text format, a suitable MMI (Man to Machine Interface) software application has been developed.

\subsection{The W1-M3A system}

\subsubsection{Overall design and surface buoy}

The W1-M3A system is an upgrade of the existing ODAS Italia-1 buoy with main changes regarding a more powerful onboard acquisition system, a new communication technology, and marine sensors with higher quality with respect to those previously installed.

The main features of the W1-M3A system can be summarized as follows:

- location offshore and on a deep site, being about $64 \mathrm{Km}$ far from the nearest coast of La Spezia, $73 \mathrm{Km}$ far from Genoa, and on a $1377 \mathrm{~m}$ seabed;

- capability of measuring a complete set of meteorological parameters;

- capability of measuring physical parameters of the sea down to about $50 \mathrm{~m}$;

- capability of measuring physical and chemical properties of the sea water by means of a multiparametric device close or on the damping disk of the buoy, i.e. at a favorable depth for measuring, for instance, the maximum of fluorescence;

- transmission of acquired data in NRT to the station ashore by means of a dedicated satellite phone link;

- on-line application of data quality control procedures on the acquired data and their forwarding to the data management centre.

ODAS Italia-1 is a large spar buoy specifically designed for air-sea interaction studies and the collection of meteorological data even in rough sea (Fig. 4). Stability is the basic feature of this type of buoy with respect to the other more classical approach based on discus-shaped buoys (Berteaux, 1976).

The buoy consists of a main steel pole body divided into four sections firmly joint by flanges and bolts. The three upper sections are water-tight, and one of them, the one in the middle, has a thicker portion to improve buoy stability and buoyancy. The fourth section is filled with water and has a stabilizing disk which, for the significant mass of water it moves, dampens the buoy vertical motion. A $1300 \mathrm{Kg}$ ballast 


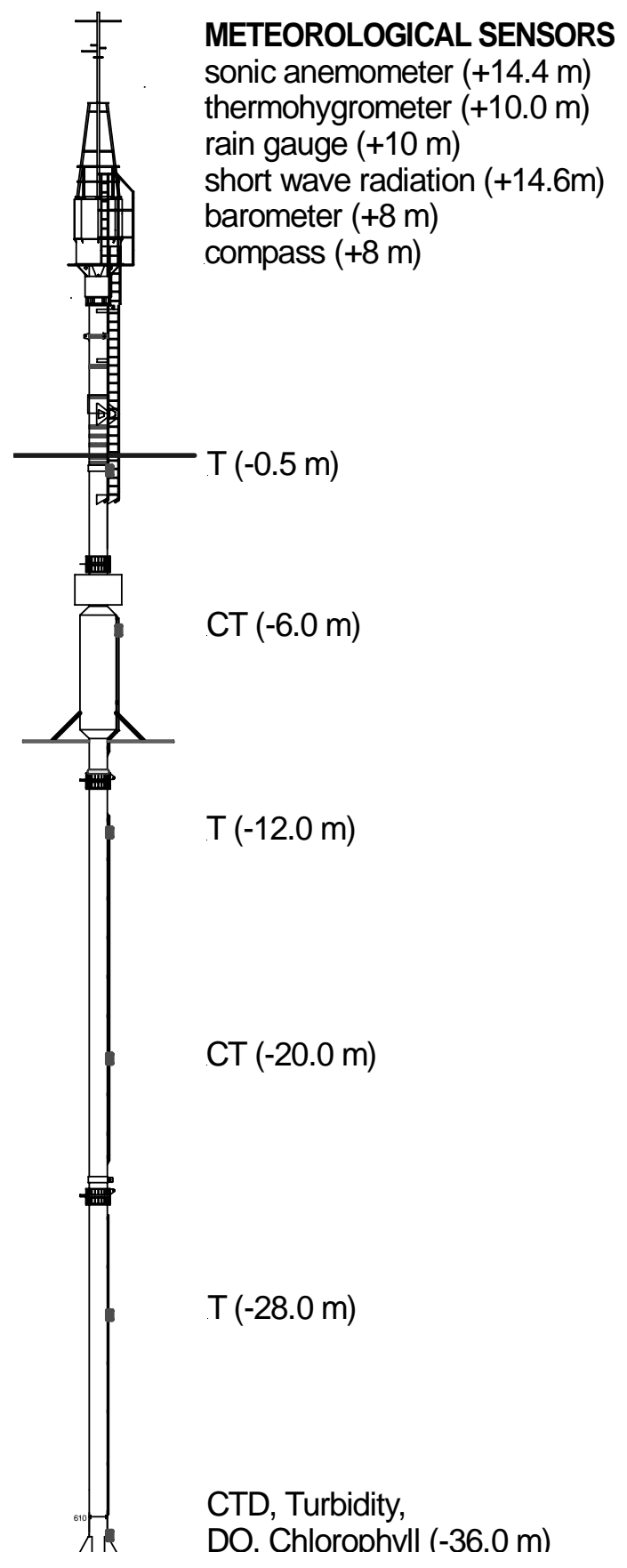

Fig. 4. Outline of the W1-M3A system.

hangs from below this segment. The three water-tight floating sections were filled with a closed-cell foam pre-shaped in pieces $1 \mathrm{~m}$ long of diameter close to inner diameter of the buoy and sealed in strong double nylon bags. The chosen foam was dense enough to limit, in case of complete flooding of the section, the volume reduction to less than $10 \%$. This would cause the buoy to sink few meters with several meters of reserve buoyancy still available.
The mooring line is an $\mathrm{S}$ shape slack mooring usually employed to moor surface buoys in deep ocean. The basic configuration of this type of moorings consists in a heavy upper part whereas the lower part is buoyant or supported by glass balls to avoid possible piling on the ocean floor. The slack configuration ensures that the surface buoy is able to withstand even strong transversal thrusts, without sinking.

\subsubsection{Instruments and sensors}

The scientific payload of W1-M3A can be grouped into three classes depending on the type of measurements produced and/or on their position along the buoy's body. Figure 4 shows the technical drawing of the buoy with the notes about the onboard equipment. The meteorological set composed by precision spectral pyranometer, wind speed and direction sensors (mounted at about 14.60 and 14.40 m over mean sea level, respectively), two piezoelectric barometers, two thermo-hygrometers (one in a standard shield, the other in a ventilated shield). Marine sensors set includes six temperature sensors positioned along the buoy body (one on the sea surface, the others at $-6.0,-12.0,-20.0,-28.0,-36.0 \mathrm{~m}$, respectively) and three echosounders at about $-9.4 \mathrm{~m}$ on $120^{\circ}$ supports measure the distance from the sea surface above. The wave form on the sea surface is constructed from data obtained with these sensors after buoy response to the sea and buoy motion measured by other sensors are accounted for. A SBE-16 multiparametric probe (CTD plus turbidity, dissolved oxygen, chlorophyll) is installed at about $-36.0 \mathrm{~m}$ depth close to the damping disk of the buoy whereas other 2 temperature-conductivity sensors (SBE-37) are placed at -6.0 and $-20 \mathrm{~m}$ depth, respectively. The last set of sensors includes a double axis inclinometers, a compass, and a GPS receiver. The power supply system is monitored by a voltage sensor indicating battery charge and by a group of electronic current detector sensors measuring power generated by each photovoltaic panel and the wind turbine.

Since the acquisition system was designed with some modularity, other types of measurements could be acquired provided the feasibility of the sensor's installation onboard the buoy, the availability of the necessary power supply and the capacity of measuring and treating the type and the amount of data extracted by the sensor.

\subsubsection{Control systems and data telemetry}

The control and telemetry equipment of W1-M3A can be grouped into the following subsystems:

- the control and acquisition module devoted to the control of all the equipment installed onboard and to the acquisition of the measurements;

- the communication system providing the necessary tools for exchanging commands, information, and data with the remote system ashore; 
- the power supply system charging the battery pack that powers all the electronic devices onboard the buoy;

The core of the control and acquisition system is a National Instruments Compact Fieldpoint intelligent controller for reliable distributed or stand-alone deployment with industrial ratings for what concern temperature range, shocks and vibration. Several acquisition and conditioning boards can be connected to the controller through a backplane.

The W1-M3A system employs a Globalstar duplex satellite data modem that provides two-way business-to-business Internet communications with land or marine based equipment via direct dial-up or direct internet access to communicate with the receiving station ashore. Globalstar is a low Earth orbit satellite constellation for telephone and lowspeed data communications, similar to (and competing with) the Iridium satellite system.

All the equipment onboard the buoy is powered by a combination of solar and wind energy that charges a 12V@ $180 \mathrm{AH}$ battery pack. Eight photovoltaic panels having a typical peak power of $60 \mathrm{Watt}$ each and arranged around the buoy upper part together with a wind generator provide the current. The charge of the battery is controlled by four shunt regulators each one acting on a couple of panels and a regulator for the wind generator.

\section{Data transmission and quality control}

The NRT quality control procedures defined as Data Quality Control Level 0 and hereafter named DQCL0, are those developed during the MFSPP and MFSTEP projects (documentation available through http://www.poseidon. ncmr.gr/M3A/Documents/M3A-documents.htm or through the MERSEA site http://www.mersea.eu.org/Insitu-Obs/ DQCL0_M3A.pdf). The aim of these procedures is to assure the quality of the data by means of the application of a series of tests to identify erroneous data, establish, and identify corrupted data and to point out malfunction of sensors. These tests consist of checks on individual or consecutive data points and can be classified in four types: 1) instrument errors, 2) physical limits of the data, 3) rate of change, and 4) stationarity of data, i.e.

1. the values have to lie within the instruments ranges,

2. the values have to lie within the prefixed physical ranges,

3. the values have to respect a rate of the change in the time,

4. the values cannot be constant over a time period relevant to the specific parameter.

Each check is performed in sequence and only if the previous one has been successful. Each of the automatic quality control checks generates a flag when the check fails and

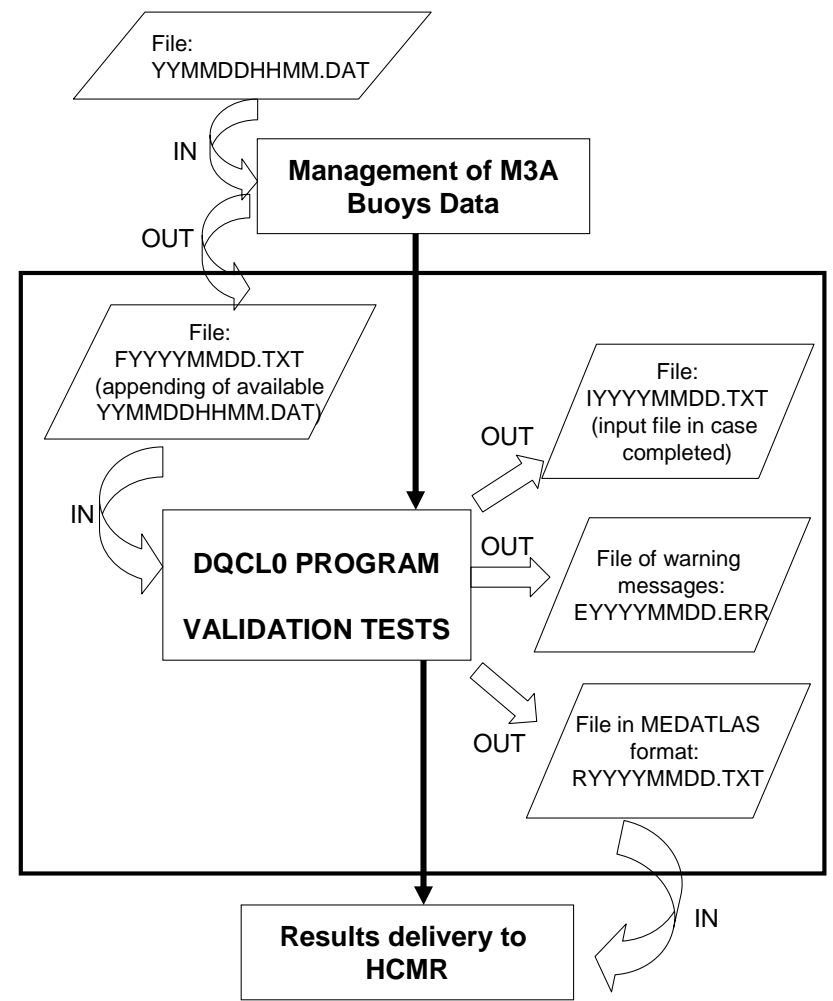

Fig. 5. Sequence of the M3A data automated quality control procedures.

the flag is ascribed to the data point failing the check. Data are considered correct when they have successfully passed through all the tests. No editing of invalid data or replacement of missing values is performed. The result of this procedure is an output using the MEDATLAS data format and named by a suffix NR followed by the date of measurement: NR20040701.TXT (Fig. 5).

The DQCL0 is activated by an automatic procedure, running on a computer of each centre: HCMR (Athens-Greece), OGS (Trieste-Italy) and CNR (Genoa-Italy) that daily:

- collects files data coming from the corresponding M3A buoy,

- prepares input file for the data quality control program,

- activates the data quality control program providing the day's date,

- transmits the results (MEDATLAS file) to the collection centre: HCMR Athens-Greece.

The sampling interval and type of measurement is different for each system/instrument (one hour in most cases) but the assembly of data by the control unit of each surface buoy and the consequent transmission is carried out every three hours (Fig. 6). The final product is one file per day containing all 


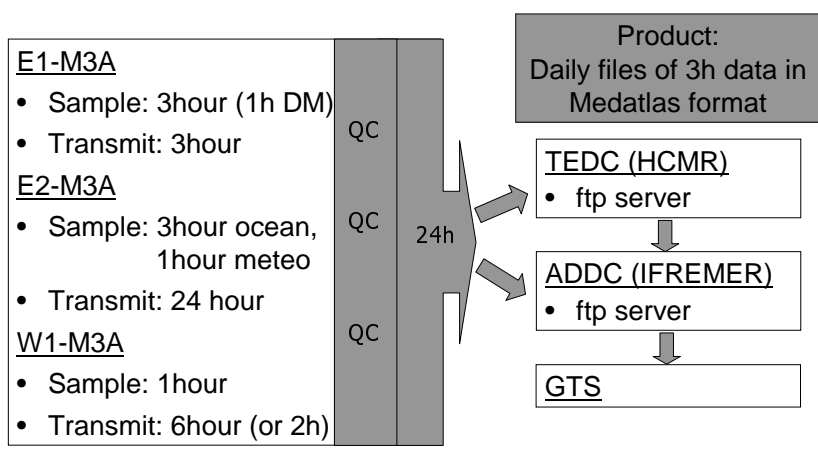

Fig. 6. Overview of M3A data sampling and dissemination procedures.

the 3-hourly data. More detailed information can be found in Cardin and Perini (2005).

An automated ftp procedure has been set up for daily transfer of the data to the Coriolis data centre (http://www. ifremer.fr/coriolis/) and inclusion in the central MFSTEP and MERSEA information systems. The same procedure is followed for the delayed mode data received after each maintenance mission and after the completion of post calibration procedures (mainly applied on the chlorophyll-a and dissolved oxygen data) approximately every two months. The complete data records are stored by the instrument's loggers and are downloaded during each maintenance.

In order to handle the amount of data transmitted from the buoy to the fixed station either through the Iridium/Globalstar satellite system or GSM network, a simple UNIX program has been created and inserted in a cron-tab file. This program performs the following steps:

- it verifies daily the existence of all synoptic files and their completeness

- if this is true, an unique file containing all the data is created;

- this file together with the one of the previous day is used as input files for the NRT quality control (DQCL0) procedure;

- after the DQCL0 procedure is applied and no errors are detected an output file in Medatlas format is created;

- subsequently the DQCL0 data files are transmitted to HCMR via an automatic ftp procedure from the two buoys (E2-M3A and W1-M3A);

- an email message containing the log file is sent to the data transmission responsible scientists .

\section{Operation during 2004-2006}

During 2004 the three buoy systems have been upgraded to the M3A configuration and prepared to contribute to the MF-
STEP TOP phase (Targeted Operational Period, September 2004-March 2005). The network operation was sustained after the TOP period of MFSTEP as it contributes to the observing system of the MERSEA project (Desaubies et al., 2005) since September 2005. The operation and performance of the three systems until the end of 2005 is described in the following paragraphs.

\subsection{E1-M3A operation}

The E1-M3A system was deployed by R/V Aegaeo in the south Aegean (Cretan) Sea 21 July 2004. The system operated during the TOP phase of MFSTEP and two maintenance cruises were carried out during that period (November 2004 and March 2005). A series of shorter maintenance visits aiming to fix system malfunctions were also performed using a small speed boat that allows easy approach to the surface buoy.

The overall performance of the E1-M3A system up to October 2005 is schematically summarized in Fig. 7. The main problem during that period was the performance of the surface buoy that discontinued its operation between September 2004 and March 2005 and from August 2005 onwards. This did not allow collection of surface and meteorological data during these periods and delivery of NRT data. However, the "deep" sensors of lines 1-2-3 continued their operation and their data were made available in delayed mode. The first malfunction of the buoy was due to a failure of the central CPU (based on a i386 processor). It was detected in mid September 2004 and an emergency visit with speed boat was carried out on 19 September 2004. Since the problem could not be solved on-site, the surface buoy was recovered and replaced by a spare one (minimum configuration: light, reflector etc.) during the maintenance cruise of November 2004. Following a replacement of the CPU the surface buoy was redeployed during the next maintenance cruise of March 2005. The NRT delivery of data continued up to mid August 2005 when the operation of the surface buoy was again halted due to malfunction of the buoy energy supply system.

Secondary problems during the same period were: a) the operation of the $40 \mathrm{~m}$ CTD probe of line 2 due to power problems; during the first two maintenance visits it was not possible to distinguish if the problem was due to badly preserved batteries or energy over-consumption and, thus, it was decided to replace the batteries and continue the operation of the probe; during the last maintenance cruise of November 2005 it was decided to remove the specific device and send it to the manufacturer for further inspection and repair b) the dissolved oxygen and turbidity sensors of the $65 \mathrm{~m}$ probe did not provide reliable data (out of range, repeating spikes). The problem persisted after the usual maintenance of the sensors and is most likely attributed to material failure (connectors) c) the same applied for the dissolved oxygen, turbidity, PAR and chlorophyll-a sensors of the $115 \mathrm{~m}$ probe after May 2005 . 


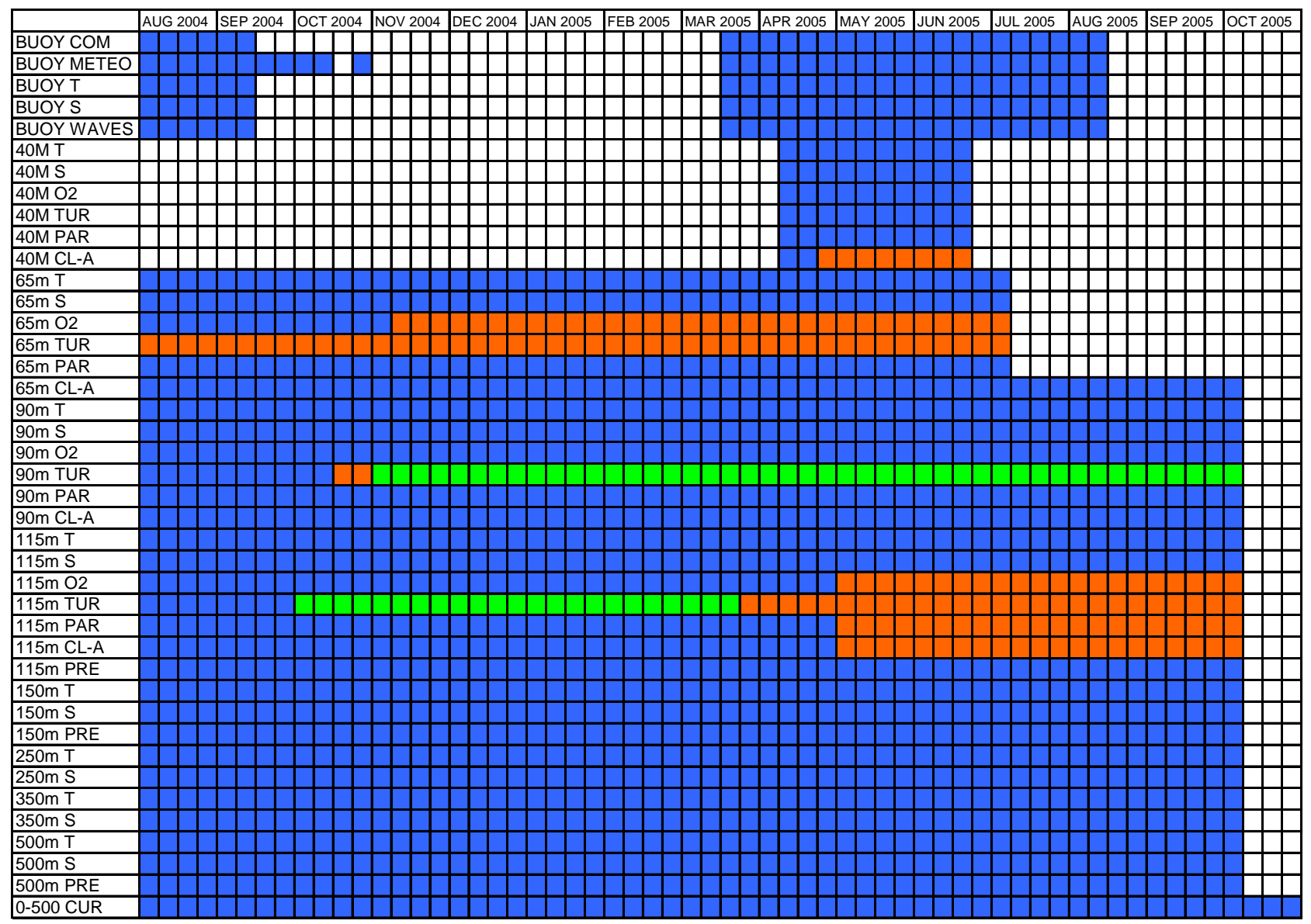

Fig. 7. Performance of E1-M3A system up to October 2005: blue: Good operation/data; red: bad data; green: need for calibration; white lack of data due to sensor/system malfunction. The color code is the same as in Fig. 5 of Nittis et al. (2003).

The overall performance of the E1-M3A system has been improved compared to its pilot operation in 2000-2001 (Nittis et al., 2003) mainly because the antifouling methods improved the quality of biochemical data. However, the instrumentation of the system is ageing and, thus, the number of failures that need major and/or factory repair is increasing. A major upgrade or replacement of system components is, therefore, necessary in the near future.

A subset of the data collected by E1-M3A during the 15 months operation under MFSTEP is presented in Fig. 8. A comparison between the temperature and salinity time series of 2004-2005 and those of 2000-2001 can be used to estimate the interannual variability of water masses and their vertical structure in the Cretan Sea (the temperature and salinity scale used in Fig. 8 is the same used by Nittis et al., 2006). The upper $100 \mathrm{~m}$ layer (seasonal thermocline for the Cretan Sea) of summer 2004 is significantly warmer compared to 2000 (by $3-4^{\circ} \mathrm{C}$ ) and 2005 (approximately $1-2^{\circ} \mathrm{C}$ for June-July for which complete timeseries are available for both years). The variability is strong even in the $100-150 \mathrm{~m}$ layer that presents a remarkable warming in 2001, possibly attributed to intensification or westward displacement of the anticyclonic component of the dipole that controls the circulation in the Cretan Sea (Cardin et al., 2003). During the approximately 4 years of E1-M3A operation, deep mixing has been recorded only during winter 2005 . The south Aegean Sea is an area when the warm and saline Cretan Intermediate Water (CIW) is formed during wintertime mixing up to 300$500 \mathrm{~m}$ (Theocharis et al., 1999). Such mixing event has been recorded during late winter 2005 (mid March to mid April, Fig. 8) down to a depth of $350 \mathrm{~m}$.

Interannual changes of the salinity structure can be detected in both the subsurface and intermediate layers (Fig. 8b). The low salinity subsurface signal of the Atlantic Water (AW) is much weaker in 2004-2005 compared to the 2000-2001 period (although the $40 \mathrm{~m}$ timeseries is missing in the second period); the salinity minimum in 2004 is $38.75-$ 38.80 compared to 38.6 in $2000-2001$. The CIW salinity maximum is observed in 2000 at a depth of $250 \mathrm{~m}$ while during the other 3 years it appears to be at $150 \mathrm{~m}$ and with slightly increased values (39.05-39.1). Finally, the system was able to collect long time series of PAR data (Fig. 8c) 
Temperature at $40,65,90,115,150,250,350$ and 500 meters

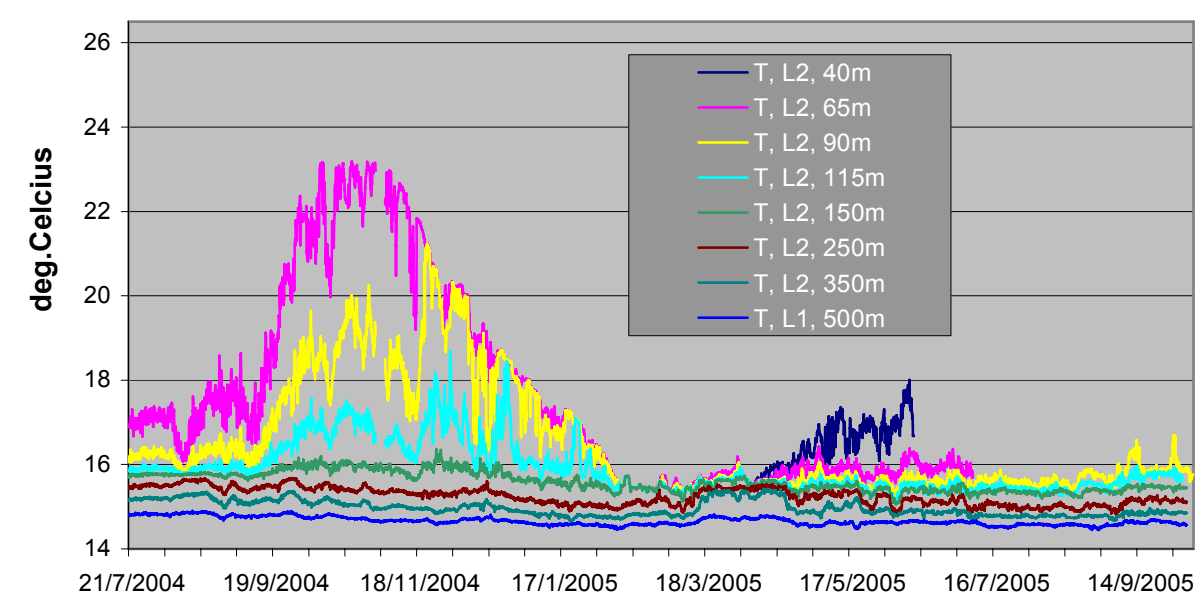

Salinity at $40,65,150$ and 250 metres

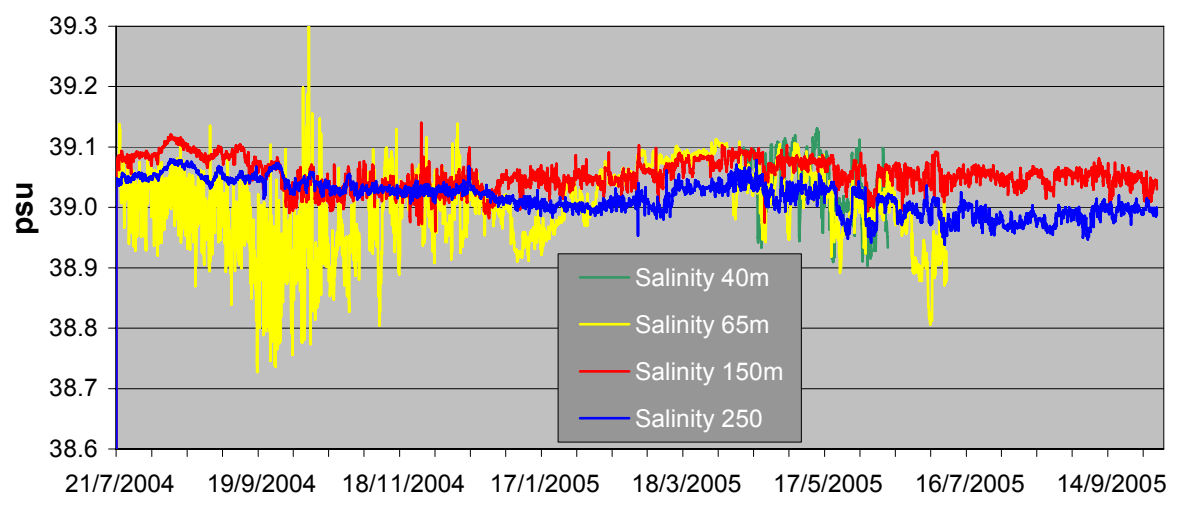

PAR at 65, 90 and 115 metres

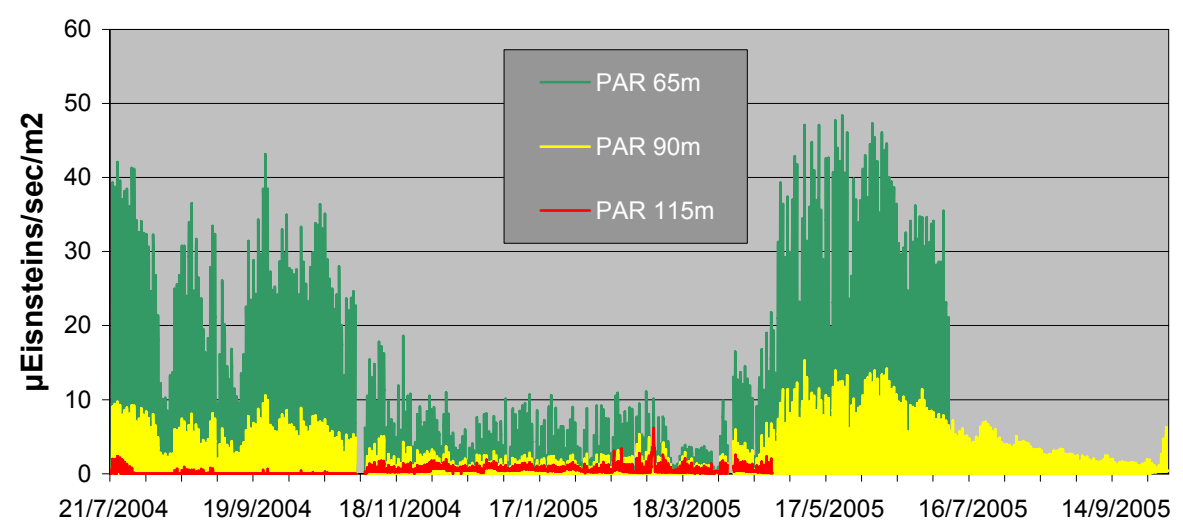

Fig. 8. Selected time series from the E1-M3A system (a) temperature at 8 depths (b) Salinity at 4 depths and (c) PAR at 3 depths (40 m omitted due to short duration).

offering a valuable quantification of the diurnal, synoptic and seasonal variability of light availability in the Cretan Sea euphotic zone. 


\subsection{E2-M3A operation}

The E2-M3A buoy was put in operation in early 2004. During January 2004 the buoy was transferred from Trieste to Bari harbour and on 16 February 2004 the buoy was deployed at the site selected for the TOP period (Southern Adriatic Sea, offshore Brindisi, $1050 \mathrm{~m}$ depth) and mission started. In this configuration the scientific payload included the meteorological station and the hull-mounted CT. The buoy operated with full reliability until August 2004, when the mission was stopped to allow the recovery of the buoy and its transport to the port of Bari for the system upgrade towards the complete M3A configuration. During the mission, all scientific data were downloaded from the buoy via daily interrogation from Tecnomare (system manufacturer) and then disseminated by OGS on a weekly basis through the site http://doga.ogs.trieste.it/boma_mfstep/.

Contemporary, tests were performed in laboratory to verify the operation of the new hardware and software implemented on the buoy so as to manage the additional functionalities imposed by the E2-M3A configuration: management of CTD chain and the Nutrient analyser, second telemetry allowing automatic daily transmission of data to OGS ftp server and additional status monitoring sensors.

Being the buoy physically not available (as under operation at sea), these tests were carried out connecting the new subsystems to a second data acquisition and control unit, specifically developed by Tecnomare for this purpose. In this way the buoy operation could be simulated and the new functionalities verified. These tests were carried out in Tecnomare workshop, during the period January-August 2004, in parallel with the basic functional tests.

One important part of the test was focused on the new scientific payload to be added on the buoy basic configuration, and in particular on the Nutrient analyser requiring a dedicated activity to define its correct set-up, validate its operation and ensure optimal interface with the water sampling system implemented on E2-M3A. This activity started on April 2004, with some delay with respect to the project schedule, due to the necessity to send the instrument to the manufacturer for some upgrade and servicing work. Test on the CTD probes were quite simpler, being the sensors "offthe-shelf" and not requiring any specific set-up.

The system was re-deployed at the original site at the beginning of September and a new mission started. The first week the system worked perfectly showing promising data (Fig. 9). During the last week of September, following a strong storm, major failures to some sensors were observed (CT sensor chain failure on 24 September 2004, 10:00:00 LT for inductive cable breakage; meteorological station failure on 24 September 2004, 23:00:00 LT, reason still unknown). Connection to the buoy was however maintained, allowing continuous monitoring of buoy position and status parameters. In the subsequent hours, the buoy changed position and the reason is still unknown. On 25 September 2004 the mis-
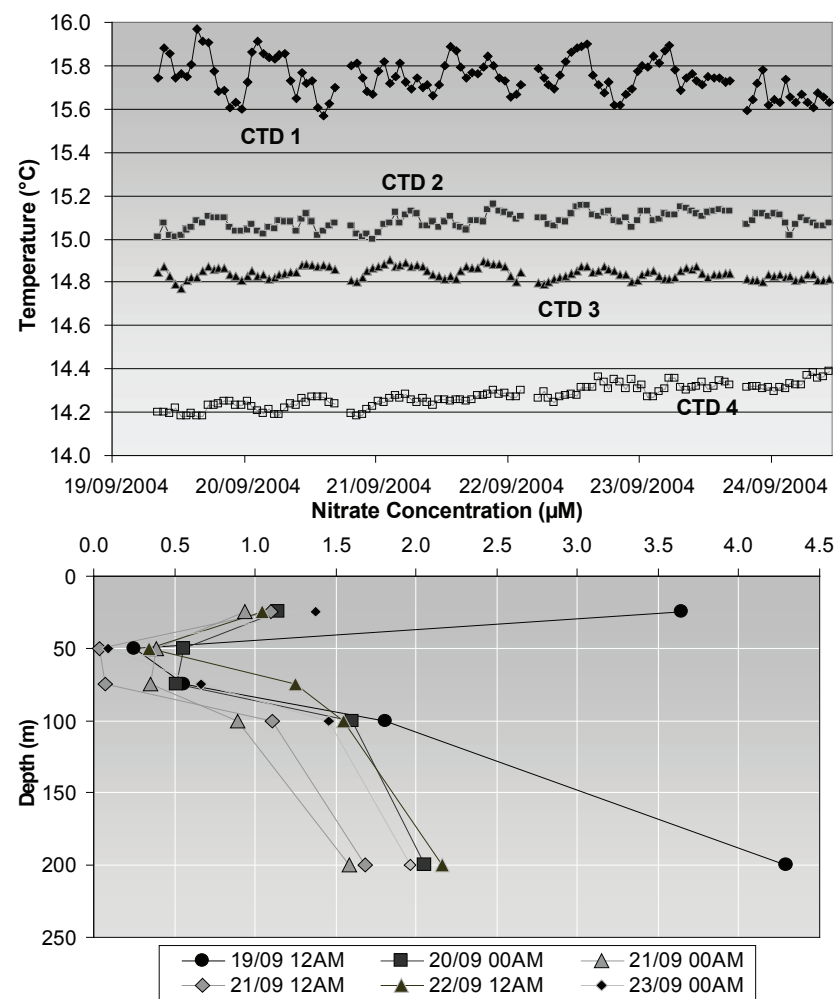

Fig. 9. Examples of E2-M3A data: (a) temperature variability in the upper $200 \mathrm{~m}$ of the Adriatic Sea and (b) nitrate vertical profiles using the pumping system and on-board analysis.

sion was stopped and the buoy put in "idle mode" waiting maintenance intervention. Tecnomare tried to reset the connections with the buoy sensors but with no success. On 17 October 2004 it was discovered that the buoy was drifting away from the mooring position. On 19 October 2004 the buoy was found and towed into Bari harbour.

The results of inspections of the joint OGS and Insurance company team were the following: the meteorological station was lost while the entire underwater sensor line (CTD's and pumping tubes) was safe except for the CT installed at the buoy. The mooring cable was cut at the depth of $300 \mathrm{~m}$, which is difficult to explain.

The short operation of the E2-M3A during the above described period and the analysis of the data allowed:

1. To verify that most of the sensors were correctly operating, i.e.:

- The automatic daily data transmission from the buoy to the OGS ftp server;

- The automatic transmission of status messages via e-mail;

- The status parameters (battery voltage, current consumption etc.) inside the expected ranges;

- The operation of the CTD chain. 


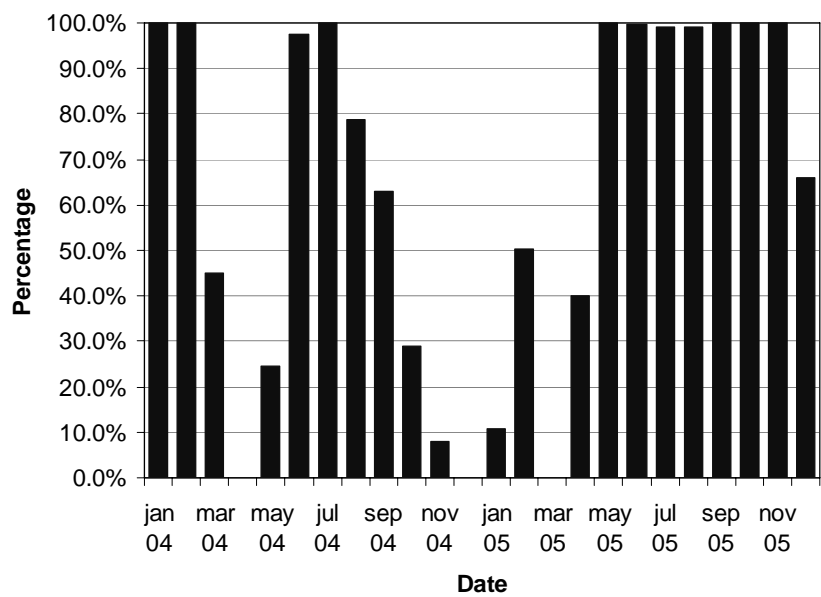

Fig. 10. Performance of W1-M3A system during the period January 2004-December 2005 in terms of percentage of available data records per month.

2. To identify some problems:

- The conductivity sensor of the CTD mounted at $100 \mathrm{~m}$ gave false readings;

- The CT mounted at buoy hull did not respond;

- All meteorological data, apart of the calculated sustained and gust values, were saved in a wrong format in the hourly message (due to a bug in the data acquisition software, identified and corrected).

3. To verify the success of the operation of the nutrient analyser integrated to the automatic water sampling system:

- The measurements at 5 depths every $12 \mathrm{~h}$ (due to the refresh and cycles shorter interval of measurements is not possible);

- The reagents stored in a fridge unit to increase autonomy;

- Apart of the first profile, there was a substantial stationarity of the nitrate levels.

\subsection{W1-M3A operation}

The main upgrade of the onboard system from the ODAS Italia-1 configuration to the M3A one occurred during a cruise in September 2004. Since then, the system operated continuously during and after the MFSTEP TOP phase and many maintenance missions were carried out with small and fast boats (November 2004, January 2005). After the MFSTEP TOP phase, another cruise was performed on April 2005 and other daily maintenance visits aiming to fix system malfunctions (affecting both the onboard controller and the sensors) and/or to perform standard operations were carried out in June, July, and August 2005.
After each mission a report is usually created detailing the operation carried out onboard and summarizing the problems faced and the solutions/decisions applied.

The overall performance of the W1-M3A system in terms of acquired and available data records up to the end of December 2005 is schematically summarized in Fig. 10 that shows the percentage of available data records per month.

During the MFSTEP TOP period and up to mid April 2005 the performance of the system was heavily affected by a power supply failure combined with a controller problem that provoked the switch off of the acquisition system without making it able to properly reboot to start again the normal procedures. After the solution was found by using a more stable and powerful power converter the on board acquisition didn't suffer any more from that problem and the percentage of acquired data raised up again almost to the maximum as expected and desired. Few missing records during the successive months are due to the maintenance activities on board the buoy for which the interruption of the acquisition service was necessary.

As an example of the data acquired by the W1-M3A system, Fig. 11 shows the temperature timeseries measured during 2005. From end of June up to the end of July only the surface sensor was in place since the others instrument were removed for calibration purposes.

It is worth of evaluating the performance of the W1-M3A system also for what concern the communication system performance. Especially for operational systems, like MFSTEP and MERSEA are, the time delay between the acquisition of the data and its availability for the assimilation into the models is particularly important. In the same way, the time delay between the creation of the data record in the remote system and its availability in the station ashore for further processing, QC, and dissemination is a meaningful indicator for the performance of the overall observing system.

In the W1-M3A system, a data record including all the acquired information of the previous hour is created at about minute 29 of each hour. As an example, the data file 03061500.dat refers to 3 June at 15:00 UTC and contains measurements collected from 14:30:00 up to 15:29:00 UTC. A transmission window is usually defined from minutes 35 up to 45 of each hour (or every two hours depending on the configuration) and during this period of time the transmission system sends the available data records to the receiving station ashore.

Table 1 shows the percentage of the data records available for further processing phases at the station ashore at fixed intervals: slightly less than $45 \%$ of records are available within $2 \mathrm{~h}$, whereas more than $80 \%$ are available within $12 \mathrm{~h}$. It has to note that these statistics take also into account those files whose reception was greatly delayed not due to problem or malfunctions in the remote system at sea but for problems in the station ashore often due to the accidental switch off of the computer during weekends or vacations. 


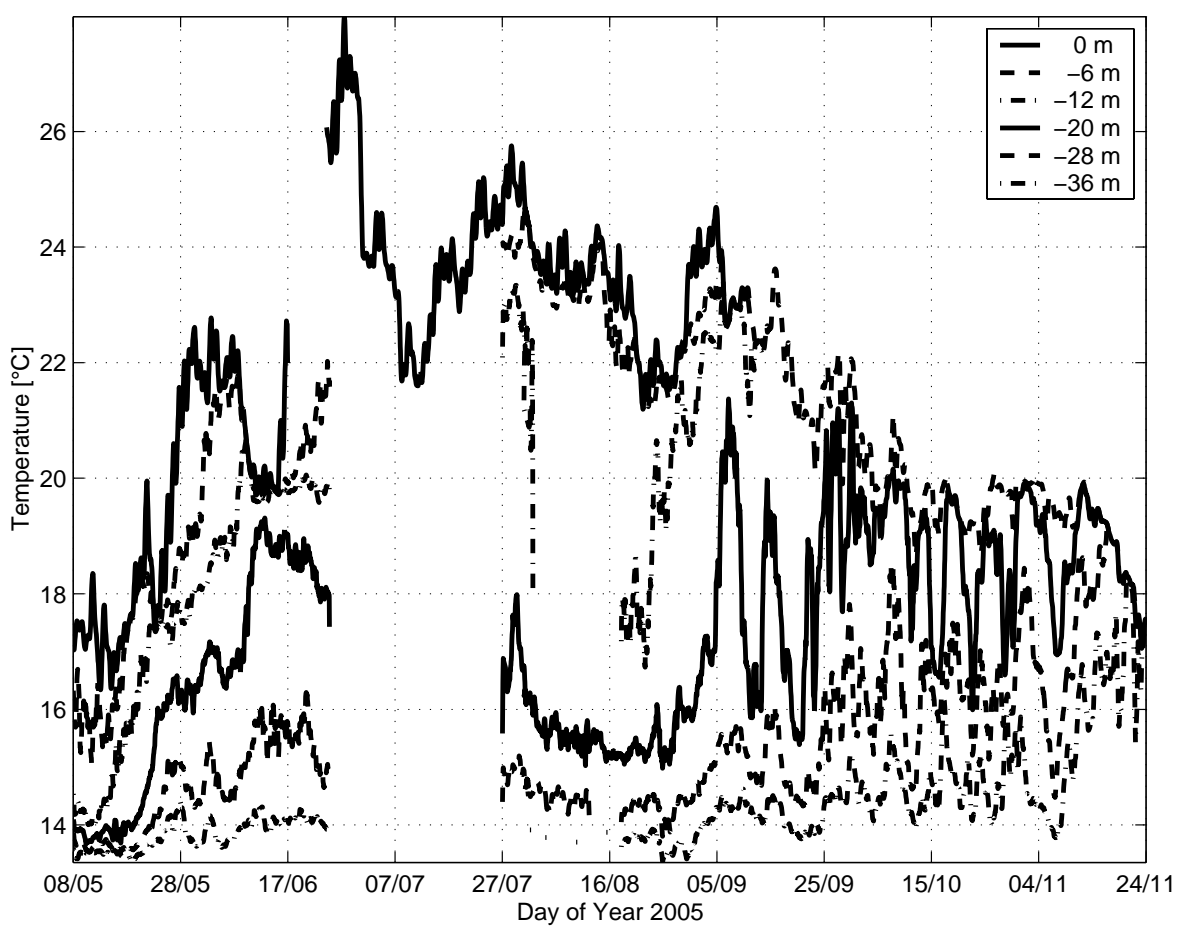

Fig. 11. Selected time series from the W1-M3A system: water temperature measured during 2005 at 6 depths.

The overall yearly success rate in collecting and transferring data from the onboard acquisition system was about $58.5 \%$ in 2004 and $74.6 \%$ in 2005 . These poor percentages have mainly to be ascribed to the difficulty in recovering from an onboard system failure when it occurs during bad weather sea condition periods making for us impossible to reach the buoy from the mainland by means of small boat.

Also the duration of each data transfer and the available baud rate are important parameters to assess the performance of the W1-M3A observing system, especially since it directly affects the cost to be sustained to efficiently operate the system. Of course they depend on the quality itself of the satellite transmission channel and on the size of the information to be transferred that usually weights from about 13 up to $17 \mathrm{~KB}$ in the actual configuration. The nominal baud rate of the Globalstar system is $9.6 \mathrm{Kbps}$ but a more conservative rate of about $7 \mathrm{Kbps}$ is suggested to be accounted for. Our estimates are substantially in agreement with these specifications reaching an average value close to $6 \mathrm{Kbps}$. The remote system placed 10648 phone calls but only for 5564 events $(52.25 \%)$ there was a real connection between the remote and the ashore systems: these numbers obviously take into account the situations in which the station ashore was not ready to receive the data (i.e., modem or PC switched off) as well as the cases in which the connections were not established due to a poor quality of the transmission channel or the two modems failed to positively negotiate the communication. In case of connection between the two systems, there was
Table 1. Efficiency of the W1-M3A transmission system expressed in percentage of available data records within fixed time limits.

\begin{tabular}{lll}
\hline & Nr. of records & $\%$ \\
\hline Records transmitted within 2 h & 2279 & 44.63 \\
Records transmitted within 4h & 3545 & 69.43 \\
Records transmitted within 6h & 3927 & 76.91 \\
Records transmitted within 12 h & 4179 & 81.84 \\
Records transmitted within 18 h & 4284 & 83.90 \\
Records transmitted within 24 h & 4348 & 85.15 \\
Records transmitted within 48 h & 4472 & 87.58 \\
Records transmitted within 72 h & 4564 & 89.39 \\
Records transmitted within 96 h & 4624 & 90.56 \\
Records transmitted after 96h & 482 & 9.44 \\
\hline
\end{tabular}

a successful data transmission in 4361 cases $(78.38 \%)$. In the remaining cases the communication was lost during the connection. The average duration of a connection is about 51.30 s with an average cost per connection of $0.86 €+$ VAT.

\section{Conclusions and future plans}

The MFSTEP project developed the basis for long-term, coordinated operation of multi-sensor timeseries stations in the Mediterranean Sea. Building on the experience of the prototype M3A system's operation in the Eastern Mediterranean 
during 2000-2001 and investing on ongoing national efforts for operational monitoring, the system has been expanded with two more stations in the Central and Western Mediterranean Sea. The strategy to upgrade existing monitoring platforms reduces the overall development cost and supports the sustainability of the network in the long term.

The three systems have several differences, especially in terms of design and technological characteristics, but share the same sampling strategy, quality control and data management procedures. Two of the systems focus on biochemical processes in the euphotic zone, in support of regional preoperational ecosystem models' development (Triantafyllou et al., 2003) while the third one is focusing on air-sea interaction processes. The subsurface and/or upper thermocline physical data (temperature, salinity) of the three stations are of the same quality, allowing future inter-comparison studies on basin scale processes, such as interannual variability of ocean dynamics in response to large scale atmospheric forcing.

Overall, and despite the E2-M3A accident and malfunctions of individual components, the M3A network has managed to provide high quality and long time series for most of the targeted parameters. The antifouling methods and quality controls/checks tested by the E1-M3A system have significantly improved the quality of optical measurements, especially for chlorophyll-a and light attenuation measurements that had the most important problems during the pilot operation (2000-2001). It has been, however, proved that the antifouling methods based on bromine have a limited duration ( $\sim 3$ months) and additional methods should be considered if a longer maintenance time interval is desired. The innovative pumping system and the analytical apparatus used by the E2-M3A station had a good performance, allowing the automatic collection, for the first time to our knowledge, of nitrate vertical profiles from an open sea buoy. Even though this station functioned less than a month in the complete E2-M3A configuration, it showed to be reliable in providing valid data. The meteorological and surface temperature/salinity long time series collected during the first part of 2004 (test phase) made possible comparison between in-situ data models results, and allowed detection of synoptic variability mostly missed during the low resolution monitoring. The W1-M3A system showed to be able to collect reliable data for long time periods with reasonable costs and sustainable maintenance activities. All the different modules constituting the observing system have been tested and also the processing chain have been validated allowing the W1-M3A system to be the first Mediterranean open-sea oceanographic buoy to regularly report its data into the GTS.

The future plans include consolidation of the network operation, upgrades to improve its performance and coordination with other European and Global networks. For the E1M3A system the main problems are related to the operation of the surface buoy that has already exceeded it expected life time ( $>13$ years). Thus, its replacement is the main priority in order to sustain a long term operation with NRT delivery of data. A major upgrade is planned for 2006/2007 including: a) replacement of the surface buoy by a SeaWatch or Wavescan type buoy compatible with the POSEIDON network of the Aegean Sea (Nittis et al., 2005), b) use of a simplified single mooring configuration c) use of inductive data transfer for all instruments/sensors d) use additional antifouling methods for optical sensors, mainly based on mechanical shutters. Upgrade (a) is mandatory for the above described reasons and will guarantee integration of E1-M3A under the POSEIDON system's operational scheme, thus decreasing the costs (especially on ship time and personnel) and increasing the efficiency. Upgrades (b) and (c) are expected to reduce the system failures, especially related to internal data transmission (between E1-M3A sub-systems). These upgrades are now possible since the technology for inductive data transfer has been recently available for almost all instruments/sensors (this was not the case in 1998 when the original system design was decided). Upgrade (d) is also now possible due to technological developments on antifouling methods for optical sensors that were recently made available to the market.

The E2-M3A system has only recently recovered from the 2004 accident and entered into a pre-operational phase. Up to now, the location of the system as well as the dimension of the surface buoy proved to be very expensive considering the financial resources available. Because of this, a new surface buoy and system configuration will be introduced with the aim of reducing the cost of maintenance.

The ODAS Italia-1 buoy benefited from the upgrade to the M3A configuration, hence becoming the W1-M3A system, in terms of data acquisition efficiency and measurements overall quality. The operation of such an offshore observing system for a long and continuous period of time is itself a challenge not only for the costs (that are generally affordable) but above all for the commitment related to its maintenance since it implies the execution of regular missions that, unfortunately, can be carried out only when meteorological and sea conditions allow for them.

The M3A network is already part of the MERSEA ocean observing and forecasting system which is currently the main marine component of GMES (Global Monitoring for Environment and Security, http://www.gmes.info). Through this project the M3A network is coordinated with the ANIMATE network of the Atlantic (Send et al., 2003) forming an important component of the European contribution to the Global "OceanSites" network of timeseries stations (http://www.oceansites.org).

Acknowledgements. The work was carried out in the framework of the projects: Mediterranean Forecasting System - Towards Environmental Predictions (MFSTEP, EVK3-CT-2002-00075) and Marine EnviRonment and Security for the European Area (MERSEA-IP, AIP3-CT-2003-502885). We acknowledge the support of the European Commission DG Research that financed the projects and the General Secretary of Research and Technology of the Hellenic Ministry of Development for co-financing. 
Edited by: N. Pinardi

\section{References}

Astraldi M., Gasparini, G. P., Manzella, G. M. R., and Hopkins, T.: Temporal variability of currents in the eastern Ligurian Sea, J. Geophys. Res., 92(C2), 1515-1522, 1990.

Astraldi, M. and Gasparini, G. P.: The seasonal characteristics of the circulation in the north Mediterranean basin and their relationship with the atmospheric conditions, J. Geophys. Res., 97(C6), 9531-9540, 1992.

Bozzano, R., Siccardi, A., Schiano, M. E., Borghini, M., and Castellari, S.: Comparison of ECMWF surface meteorology and buoy observations in the Ligurian Sea, Ann. Geophys., 22, 317-330, 2004, http://www.ann-geophys.net/22/317/2004/.

Berteaux, H. O.: Buoy Engineering, John Wiley \& Sons, 319, 1976.

Cardin, V., Gacic, M., Nittis, K., Kovacevic, V., and Perini, L.: Subinertial variability in the Cretan Sea from M3A buoy, Ann. Geophys., 21, 89-102, 2003, http://www.ann-geophys.net/21/89/2003/.

Cardin, V. and Perini, L.: Data quality control procedures applied to the M3A buoys, OGS Technical Report \# 27 dd. 24/03/2005 oga18, 45, 2005.

Cavaleri, L.: The CNR meteo-oceanographic spar buoy, Deep-Sea Res., 31, 427-437, 1984.

Chiswell, S. M. and Lukas, R.: The Hawaii Ocean Time-series (HOT), EOS, Transactions of the American Geophysical Union, 71, 1397, 1990.

Desaubies, Y. and the MERSEA Consortium: The MERSEA project: Development of a European system for operational monitoring and forecasting of the ocean physics, biogeochemistry and ecosystems, on Global and Regional scales, Abstracts Book of 4th EuroGOOS Conference, 6-9 June 2005, Brest (available from IFREMER), pp 194, 2005.

Dickey, T., Frye, D., Jannasch, H., Boyle, E., Manov, D., Sigurdson, D., McNeil, J., Stramska, M., Michaels, A., Nelson, N., Siegel, D., Chang, G., Wu, J., and Knap, A.: Initial results from the Bermuda Testbed Mooring program, Deep-Sea Res. I, 45, 771794, 1998.

Gačić, M., Civitarese, G., Miserocchi, S., Cardin, V., Crise, A., and Mauri, E.: The open-ocean convection in the southern Adriatic: A controlling mechanism of the spring phytoplankton bloom, Cont. Shelf Res., 22, 1897-1908, 2002.

Glenn, S. M., Dickey, T., Parker, B., and Boicourt, W.: Longterm real-time coastal ocean observation networks, Oceanography, 13(1), 24-34, 2000.

McPhaden, M. J., Busalacchi, A. J., Cheney, R., Donguy, J. R., Gage, K. S., Halpern, D., Ji, M., Julian, P., Meyers, G., Mitchum, G. T., Niiler, P. P., Picaut, J., Reynolds, R. W., Smith, N., and Takeuchi, K.: The Tropical Ocean-Global Atmosphere (TOGA) observing system: A decade of progress, J. Geophys. Res., 103, 14 169-14 240, 1998.
Nittis, K., Tziavos, C., Thanos, I., Drakopoulos, P., Cardin, V., Gacic, M., Petihakis, G., and Basana, R.: The Mediterranean Moored Multi-sensor Array (M3A): System Development and Initial Results, Ann. Geophys., 21, 75-88, 2003, http://www.ann-geophys.net/21/75/2003/.

Nittis, K., Perivoliotis, L., Ballas, D., Soukissian, T., Papadopoulos, A., Georgopoulos, D., Mallios, A., Korres, G., Triantafyllou, G., Pollani, A., Zervakis, V., Papathanassiou, V., and Chronis, G.: POSEIDON II: A second generation monitoring and forecasting system for the Eastern Mediterranean, Abstracts Book of 4th EuroGOOS Conference, Brest, June 2005, pp 207, 2005.

Nittis, K., Perivoliotis, L., Korres, G., Tziavos, C., and Thanos, I.: Operational monitoring and forecasting for marine environmental applications in the Aegean Sea, Environmental Modelling and Software, (21), 243-257, 2006.

Petihakis, G., Drakopoulos, P., Nittis, K., Zervakis, V., Christodoulou, C., and Tziavos, C.: M3A system (2000-2005) - operation and maintenance, Ocean Sci., 3, 117-128, 2007, http://www.ocean-sci.net/3/117/2007/.

Pinardi, N. and Flemming, N. C.: The Mediterranean Forecasting System Science Plan, EuroGOOS Publications No. 11, Southampton Oceanography Centre, Southampton, ISBN 0904175-35-9, 48, 1998.

Pinardi, N., Allen, I., Demirov, E., De Mey, P., Korres, G., Le Traon, P.-Y., Maillard, C., Manzella, G., and Tziavos, C.: The Mediterranean ocean forecasting system: first phase of implementation (1998-2001), Ann. Geophys., 21, 1-18, 2003, http://www.ann-geophys.net/21/1/2003/.

Pinardi, N. and MFSTEP partners: Mediterranean Forecasting System Toward Environmental Prediction (MFSTEP): Status of Implementation, Abstracts Book of 4th EuroGOOS Conference, 69 June 2005, Brest (available from IFREMER), 112, 2005.

Send, U., Edwards, M., Hydes, D., Karstensen, J., Lampitt, R., Llinas, O., Muller, T., Olafsson, J., Ratmeyer, V., and Valdimarsson, H.: The Animate Team: Real-time interdisciplinary timeseries observations in the Northeast Atlantic, EGS-AGU-EUG Joint Assembly, Abstracts from the meeting held in Nice, France, abstract\#14747S, 6-11 April 2003.

Sparnocchia, S., Schiano, M. E., Picco, P., Bozzano, R., and Cappelletti, A.: The anomalous warming of summer 2003 in the surface layer of the Central Ligurian Sea (Western Mediterranean), Ann. Geophys., 24, 443-453, 2006, http://www.ann-geophys.net/24/443/2006/.

Tecnomare: Progetto 3.3.1.5 - Realizzazione di un sistema fisso di monitoraggio di grandi dimensioni - Rapporto finale, Project BOMA, Technical report (internal) A0954-REL-A900-009.0 Tecnomare, 20, 2004.

Theocharis, A., Nittis, K., Kontoyiannis, H., Papageorgiou, E., and Balopoulos, E.: Climatic changes in the Aegean Sea influence the Eastern Mediterranean thermohaline circulation, Geophys. Res. Lett., 26, 1617-1620, 1999.

Triantafyllou, G., Petihakis, G., and Allen, J. I.: Assessing the performance of the Cretan Sea ecosystem model with the use of high frequency M3A buoy data set, Ann. Geophys., 21, 365-375, 2003, http://www.ann-geophys.net/21/365/2003/. 